\title{
Article \\ Effect of the Thermomechanical Treatment on the Corrosion of UNSM Processed Inconel 718: An Electrochemical Study
}

\author{
Ulises Martin, Jacob Ress and David M. Bastidas *i)
}

National Center for Education and Research on Corrosion and Materials Performance, NCERCAMP-UA, Department of Chemical, Biomolecular, and Corrosion Engineering, The University of Akron, 302 E Buchtel Ave, Akron, OH 44325-3906, USA; um11@uakron.edu (U.M.); jtr45@uakron.edu (J.R.)

* Correspondence: dbastidas@uakron.edu; Tel.: +1-330-972-2968

Citation: Martin, U.; Ress, J.;

Bastidas, D.M. Effect of the

Thermomechanical Treatment on the Corrosion of UNSM Processed Inconel 718: An Electrochemical Study. Metals 2021,11, 1488. https:// doi.org/10.3390/met11091488

Academic Editor: Changdong Gu

Received: 21 August 2021

Accepted: 16 September 2021

Published: 18 September 2021

Publisher's Note: MDPI stays neutral with regard to jurisdictional claims in published maps and institutional affiliations.

Copyright: (c) 2021 by the authors. Licensee MDPI, Basel, Switzerland. This article is an open access article distributed under the terms and conditions of the Creative Commons Attribution (CC BY) license (https:// creativecommons.org/licenses/by/ $4.0 /)$.

\begin{abstract}
In this work, the influence of thermal (TT), mechanical, and thermomechanical (TMT) treatments using the ultrasonic nanocrystal surface modification (UNSM) on the corrosion protection properties of Inconel 718 was studied, correlating the changes in the electrochemical properties with the promoted microstructure. The UNSM treatment had a grain refinement effect on the top surface, reducing the grain size from 11.5 to $7.4 \mu \mathrm{m}$ for the first $10 \mu \mathrm{m}$ in depth. The high grain boundary density, due to the grain refinement, enabled a faster growth of the passive film. The impedance showed a decrease in the charge transfer resistance by three orders of magnitude, from $10^{6}$ to $10^{3} \Omega \mathrm{cm}^{2}$ for as-received to $1000{ }^{\circ} \mathrm{C}$, as the TT temperature crossed the solvus of the $\gamma^{\prime} / \gamma^{\prime \prime}$ and approached the solvus of the $\delta$-phase. The UNSM treatment lowered the pitting corrosion susceptibility, increasing the charge transfer resistance and decreasing the effective capacitance of the double layer, leading to the thickest passive film with $6.8 \mathrm{~nm}$.
\end{abstract}

Keywords: thermomechanical treatment (TMT); ultrasonic nanocrystal surface modification (UNSM); electrochemical impedance spectroscopy (EIS); Inconel 718; phase transformation

\section{Introduction}

Inconel 718 is a Ni-based superalloy widely used for aerospace and nuclear applications due to its outstanding strength, creep, fatigue, and wear resistance at elevated temperatures, close to $700{ }^{\circ} \mathrm{C}[1-4]$. Inconel 718, besides keeping its mechanical and corrosive properties under highly aggressive environments, possesses good weldability [5-7]. The strength and durability of its properties come from the single-phase austenite $(\gamma)$ matrix microstructure, thanks to the high Ni equivalent content promoting a stable $\gamma$-phase, based on the Schaeffler diagram [8]. Inconel 718 presents other secondary phases and precipitates, which influence the mechanical and electrochemical properties, among the most common of which are: gamma prime $\left(\gamma^{\prime}\right)$, a $\mathrm{Ni}_{3}(\mathrm{Al}, \mathrm{Ti})$ phase with face centered cubic (fcc) crystal structure; gamma double-prime $\left(\gamma^{\prime \prime}\right)$, a $\mathrm{Nb}_{3}(\mathrm{Al}, \mathrm{Ti})$ with body centered tetragonal (bct) unit cell; and delta $(\delta)$, a $\mathrm{Ni}_{3} \mathrm{Nb}$ phase with an orthorhombic crystal structure [9-11]. The $\gamma^{\prime \prime}$-phase is an unstable phase that grants most of the hardness to Inconel 718; however, given a thermal stimulus it transforms into the $\delta$-phase, a more stable form of the $\mathrm{Ni}_{3} \mathrm{Nb}$. While the $\delta$-phase does not provide enhanced mechanical properties and it depletes the $\gamma^{\prime \prime}$-phase density in small quantities, it is beneficial for corrosion protection [12].

In recent years, and with the aim of further enhancing the mechanical and corrosion protection properties of Inconel 718, a combination of thermomechanical treatments (TMTs) has been used. Among the most common mechanical treatments, laser shock peening, shot peening, and ultrasonic nanocrystal surface modification (UNSM) can be found [13-15]. The combination of UNSM and thermal treatments (TTs) have improved the wear, fatigue, and friction properties, giving a rougher surface with a top layer with enough plastic deformation to increase the hardness of the material. However, the microstructure was conditioned by the TT used to release part of the residual stress $[13,16,17]$. The UNSM 
promoted a high twin and dislocation density region on Inconel 718, preventing the fatigue crack to nucleate by creating barriers for the dislocation to move forward, delaying the failure of the samples [16]. Concerning the corrosion performance, the UNSM treatment has also positively influenced the corrosion behavior; among the techniques used to test it, electrochemical impedance spectroscopy (EIS) is one of the most common $[12,17,18]$. The combination of UNSM and nitriding enhanced the impedance by five times compared to the control sample, improving the pitting corrosion protection [19]. In addition, both the corrosion potential $\left(E_{\text {corr }}\right)$ and the corrosion current density $\left(i_{\text {corr }}\right)$ became $100 \mathrm{mV}$ more noble and decreased below $3 \mu \mathrm{A} / \mathrm{cm}^{2}$, respectively. In other studies, the UNSM treatment was able to improve the corrosion performance even when the sample was aged for $5 \mathrm{~h}$ at $650{ }^{\circ} \mathrm{C}$, increasing the pitting potential and decreasing the $i_{\text {corr }}$ [20]. This effect was attributed to the carbon segregation reduction that the UNSM promotes on the top surface. However, for further sensitization, the UNSM treatment reversed the trend and was detrimental for the alloy, thus reducing the effectiveness of the passive film due to the formation of deformation twins and planar defects, which had high energy and were preferential sites for the pitting corrosion nucleation.

Even with the knowledge so far on Inconel and their TTs and TMTs, there is a lack of literature on correlating the phases promoted by the processing with their influence on the corrosion behavior. For that reason, the aim of this work was to focus on the influence on the corrosion performance of Inconel 718 due to the phase transformation by thermal and/or mechanical treatments. The mechanical treatment focuses on surface modification by UNSM processing, which improves the mechanical and corrosion properties. Electrochemical monitoring combined with in depth microstructure characterization allowed for the relation of the promoted phase, based on the TTT diagram, with pitting corrosion susceptibility in $3.5 \mathrm{wt} . \% \mathrm{NaCl}$ solution. Pit morphology and density were elucidated using infinite focus microscopy and correlated with the impedance and current density monitored.

\section{Materials and Methods}

\subsection{Materials and Thermomechanical Processing}

Inconel 718 was used for this study, and its elemental composition is shown in Table 1, per the specifications of the manufacturer. Samples were cut from a $3 \mathrm{~mm}$ thick sheet with a square shape of $15 \times 15 \mathrm{~mm}^{2}$. The samples, before the TMT, were first degreased with ethanol, rinsed with deionized (DI) water, and air-dried before being polished up to grade 1200 with $\mathrm{SiC}$ sandpapers and finished with diamond powder of $1 \mu \mathrm{m}$ size. The different samples studied are identified in Table 2, where each sample is given a code corresponding with its thermal and/or mechanical treatment. Six different samples were studied: As-received sample (AR); annealed at $675^{\circ} \mathrm{C}$ for $2 \mathrm{~h}$ and then water quenched sample (TT1); annealed at $900{ }^{\circ} \mathrm{C}$ for $2 \mathrm{~h}$ and then water quenched sample (TT2); thermally treated sample at $1000^{\circ} \mathrm{C}$ for $10 \mathrm{~min}$ and then water quenched sample, this process was repeated three times (TT3); UNSM treated sample, this process was repeated three times (UNSM); and UNSM treated, thermally treated at $1000{ }^{\circ} \mathrm{C}$ for $10 \mathrm{~min}$, and then water quenched, this thermomechanical process was repeated three times (TMT). The UNSM treatment was performed with the following parameters: a tungsten carbide ball with $2.4 \mathrm{~mm}$ tip diameter, a static load of $20 \mathrm{~N}$, a scanning speed of $1000 \mathrm{~mm} / \mathrm{min}$, an amplitude of $16 \mu \mathrm{m}$ and a spacing of $10 \mu \mathrm{m}[19,20]$.

Table 1. Elemental composition of Inconel 718 (wt.\%).

\begin{tabular}{ccccccccc}
\hline Element & Al & $\mathbf{C}$ & $\mathbf{C r}$ & $\mathbf{F e}$ & $\mathbf{M o}$ & $\mathbf{N b}$ & $\mathbf{N i}$ & $\mathbf{T i}$ \\
\hline Content (wt.\%) & 0.46 & 0.03 & 17.92 & 18.80 & 3.05 & 5.05 & 53.71 & 0.97 \\
\hline
\end{tabular}


Table 2. Sample abbreviations for each of the thermal treatment (TT) and thermomechanical treatment (TMT).

\begin{tabular}{cc}
\hline Sample & Treatment \\
\hline AR & As-received \\
TT1 & Annealed at $675^{\circ} \mathrm{C}$ for $2 \mathrm{~h}+$ water quenched \\
TT2 & Annealed at $900^{\circ} \mathrm{C}$ for $2 \mathrm{~h}+$ water quenched \\
TT3 & (Annealed at $1000^{\circ} \mathrm{C} 10$ min + water quenched) $\times 3$ \\
UNSM & UNSM treated $\times 3$ \\
TMT & (UNSM treated + annealed at $1000^{\circ} \mathrm{C}$ for 10 min + water quenched) $\times 3$ \\
\hline
\end{tabular}

The different TT and TMT samples and their respective phases are labeled in the time-temperature-transformation (TTT) diagram of Inconel 718 from Figure 1 [21]. The AR and UNSM samples are expected to mainly contain a pure $\gamma$-phase matrix, as no thermal treatment was performed on them; TT1 exists well in the $\gamma^{\prime \prime}$-phase region, while TT2 is just outside the $\gamma^{\prime \prime}$ /grain boundary $\delta$-phase region and in the pure grain boundary $\delta$-phase region. Finally TT3 and TMT are outside all secondary phase regions; however, they are close to the solvus for $\delta$-phase $\left(1027^{\circ} \mathrm{C}\right)$ (see Figure 1) [22].

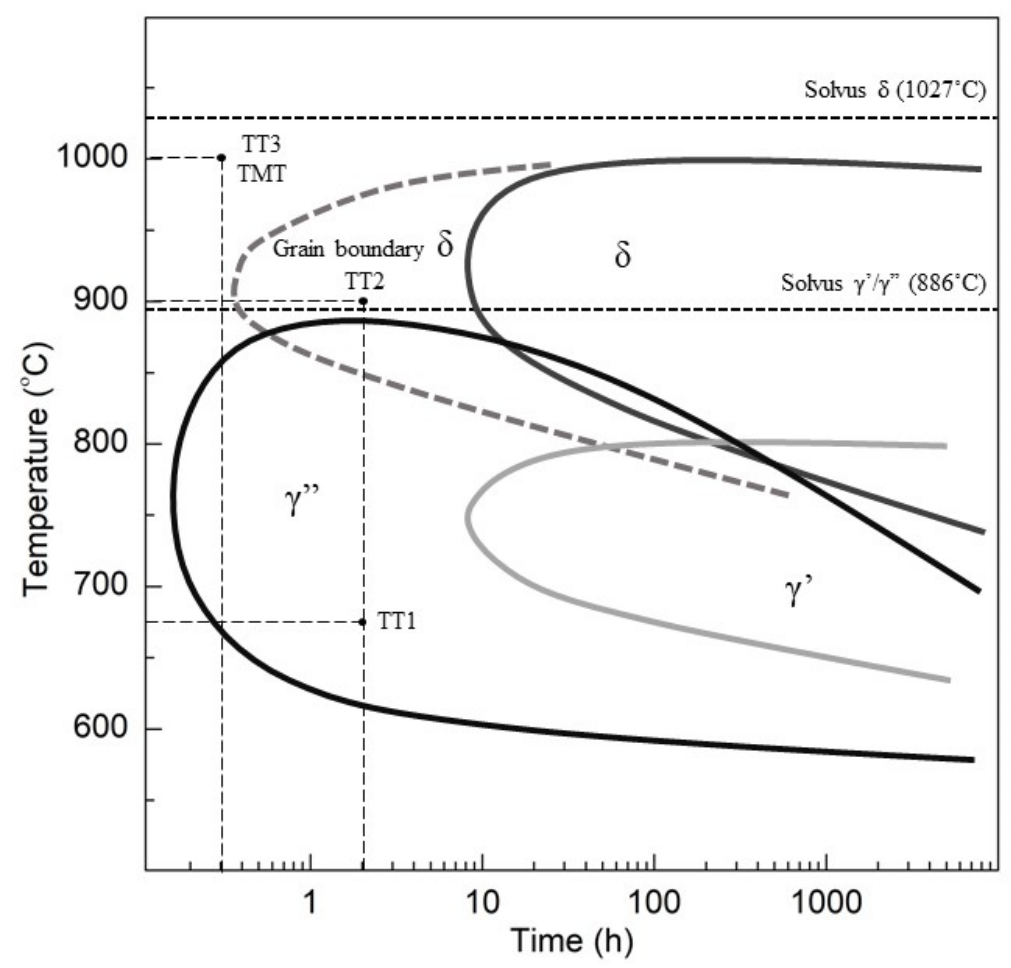

Figure 1. Time-temperature-transformation (TTT) diagram of Inconel 718 [21].

\subsection{Electrochemical Techniques}

All the electrochemical tests were performed in a three-electrode configuration cell setup with a $3.5 \mathrm{wt} . \% \mathrm{NaCl}$ electrolyte solution at room temperature $\left(25^{\circ} \mathrm{C}\right)$. The electrochemical measurements were carried out in triplicate to ensure reproducibility. A saturated calomel electrode (SCE) was used as reference electrode (RE), a graphite rod was used as counter electrode (CE), and the Inconel 718 samples were used as the working electrode (WE). The exposed area each of the samples was $1 \mathrm{~cm}^{2}$. First, open circuit potential (OCP) was monitored for $1 \mathrm{~h}$ to stabilize the $E_{\text {corr }}$, then LPR with an applied potential scan range of $\pm 15 \mathrm{mV}$ versus OCP at a scan rate of $0.167 \mathrm{mV} \mathrm{s}^{-1}$ was performed, according to ASTM G3-14 [23]. EIS measurements were carried out at an open circuit potential with a frequency range of $10^{5}$ to $10^{-2} \mathrm{~Hz}$, with an applied excitation signal of $10 \mathrm{mV}$ rms and with a scan rate of 5 steps per decade of frequency. 


\subsection{Characterization Techniques}

Vickers hardness tests were conducted to study the effect of the UNSM and thermomechanical treatment on the hardness of Inconel 718 with Wilson hardness Tukon 1202 equipment using a HV/10 cone indenter. The microstructure was studied by optical images taken with a Nikon eclipse MA 100 metallographic microscope, and a Tescan Lyra 3 XMU SEM, as well as EDX to analyze the elemental composition. IFM was used to analyze the surface after exposure to the electrochemical tests using an Alicona Infinite Focus G5 microscope. To reveal the microstructure, the samples were mounted in resin and polished with diamond powder, then immersed in an etchant solution containing $\mathrm{HCl}$ and $\mathrm{H}_{2} \mathrm{O}_{2}$ at a volume ratio of 17:1 for 15-20 s. To calculate the grain size, $\times 100$ magnification optical microscopy images were used following ASTM E112-13 [24].

\section{Results}

\subsection{Microstructure Characterization}

The optical images of the cross-section of Inconel 718, with and without the UNSM treatment, can be seen in Figure 2. The microstructure seen in both images resembles those found in the literature, mainly $\gamma$-phase matrix with some deformation twins scattered around the microstructure $[20,25]$.
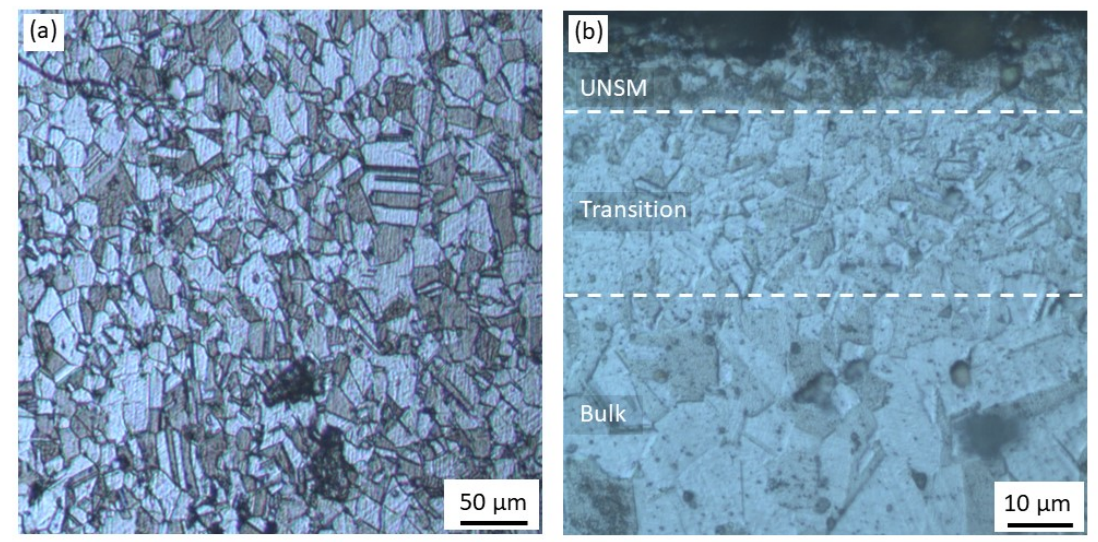

Figure 2. Optical microscopy images showing the cross-section microstructure of Inconel 718: (a) bulk of the AR $\times 10$, and (b) UNSM sample showing the three regions $\times 50$.

The $\gamma$-phase grains have polygonal equiaxed morphology, having an average grain size of $11.5 \mu \mathrm{m}$, while the UNSM treatment reduced the grain size $36 \%$, showing an average size of $7.4 \mu \mathrm{m}$ (see Figure 2). The UNSM region has an average depth after the triple processing of $10 \mu \mathrm{m}$ and a transition region of approximately $30 \mu \mathrm{m}$ for both the UNSM and TMT samples (see Figure 2b).

\subsection{Vickers Hardness}

Vickers hardness testing was performed on the AR, UNSM, and TMT samples to test the differences caused by surface modification processing. First, the AR sample was measured to have an average hardness of $285 \mathrm{HV}$ throughout the entire section (see Figure 3). Then, the UNSM sample was tested and gave the highest improvement with a hardness value of $454 \mathrm{HV}$, close to the outermost surface. However, after the first couple of $\mu \mathrm{m}$ in depth, there was a hardness gradient, decreasing as depth increases. The high plastic deformation was concentrated at the top surface, where the density of deformation twins and grain refinement was more relevant, indicating that the further away from the treated surface the less influence of the retained plastic deformation. Nevertheless, even with the decrease in hardness, the UNSM sample had a higher hardness than the AR after $200 \mu \mathrm{m}$ in depth (334 HV). The TMT sample also increased its hardness compared to the AR, increasing to $340 \mathrm{HV}$. Despite this increase, it was below the UNSM sample and returned to the initial hardness after approximately $50 \mu \mathrm{m}$. The annealing temperature of 
$1000{ }^{\circ} \mathrm{C}$ after each UNSM process reduced the effect of the UNSM treatments as the refined grains were recrystallized.

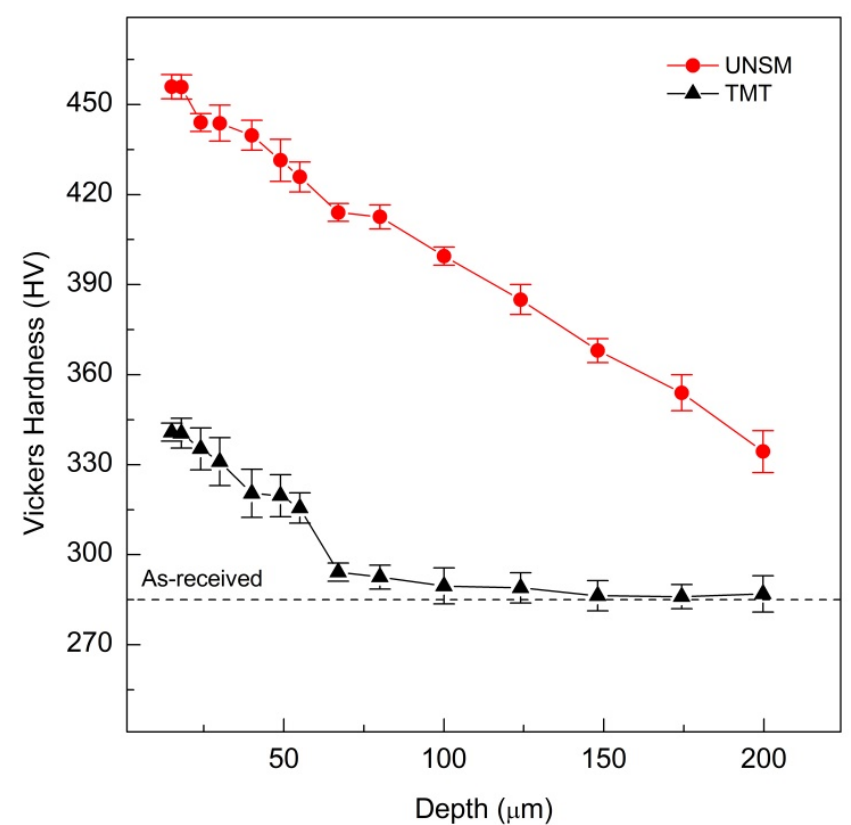

Figure 3. Vickers hardness as a function of the depth for UNSM and TMT samples.

\subsection{Linear Polarization Resistance (LPR)}

LPR was used to monitor $E_{\text {corr }}$ and $i_{\text {corr }}$, which was calculated using the Stern-Geary relationship, $i_{\text {corr }}=B / R_{\mathrm{p}}$, where $R_{\mathrm{p}}$ is the polarization resistance and $B$ is the Stern-Geary constant, which had a value of $71 \mathrm{mV}$ for Inconel 718 in $3.5 \mathrm{wt} . \% \mathrm{NaCl}$ [20]. However, the $i_{\text {corr }}$ values had to be compensated due to the ohmic drop effect of the electrolyte, as the measured $R_{\mathrm{p}}$ from the LPR also included them [26]. Figure 4 shows the combined monitoring of the $E_{\text {corr }}$ and the $i_{\text {corr }}$ for all six samples in $3.5 \mathrm{wt} . \% \mathrm{NaCl}$. The $E_{\text {corr }}$ had a decreasing trend with increasing temperature of the TT, starting at $+200 \mathrm{mV}$ versus SCE with the AR sample and becoming less noble with TT1, TT2, and TT3 with $-37,-200$, and $-390 \mathrm{mV}$ versus SCE respectively.

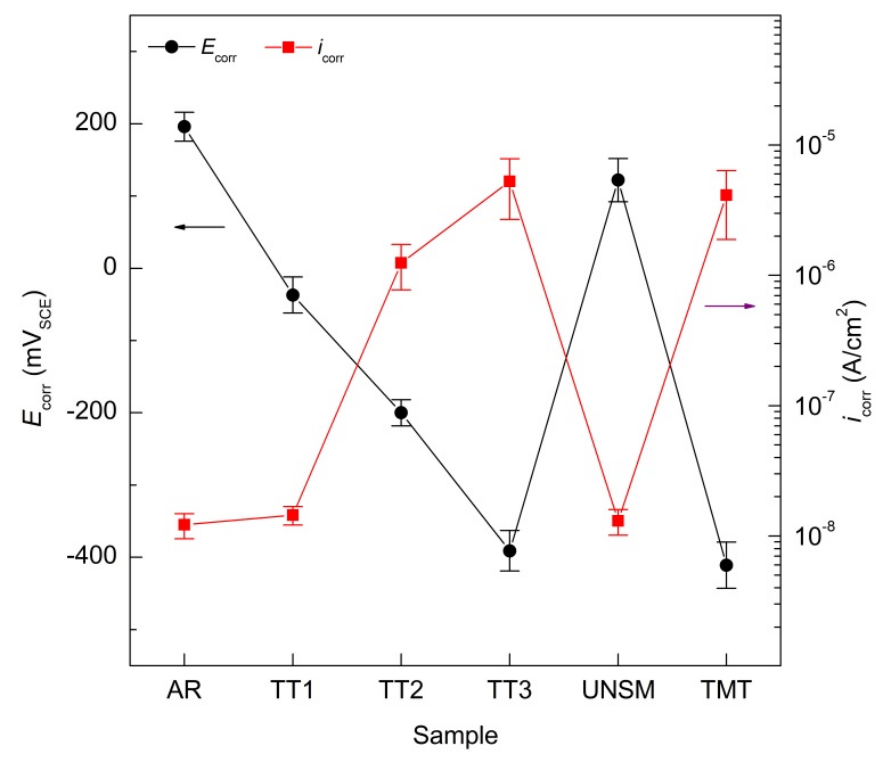

Figure 4. $E_{\text {corr }}$ and $i_{\text {corr }}$ monitoring for the different treatments of Inconel 718 in $3.5 \mathrm{wt} \% \mathrm{NaCl}$. 
Likewise, $i_{\text {corr }}$ changed accordingly with the $E_{\text {corr }}$, increasing as the temperature increased and decreasing once the UNSM was applied. Interestingly, the $i_{\text {corr }}$ also went back to the highest values for the TMT sample, showing the detrimental effect of the treatment temperature being close to the temperature of solvus for $\delta$-phase.

\subsection{Electrochemical Impedance Spectroscopy (EIS)}

EIS analysis was performed for the six different treatments to study the changes over the temperature and mechanical process of the passive film/steel interfaces, where the Nyquist plots for Inconel 718 in 3.5 wt.\% NaCl can be seen in Figure 5a. The Nyquist plots show a decreasing impedance trend with increasing thermal treatment temperature, coinciding with the behavior seen in the LPR section, with the exception of the UNSM treatment, which enhanced the corrosion performance compared to the AR sample (see Figure 5a). In order to obtain data from the passive film/steel interfaces, the impedance data were fitted to a hierarchically distributed electric equivalent circuit (EEC) with two time constants (see Figure $5 \mathrm{~b}$ ) $[27,28]$. The elements of the EEC include: $R_{\mathrm{S}}$, the resistance of the electrolyte solution, which is in series with a parallel time constant; $R_{\text {film }} / / C P E_{\text {film }}$, representing the passive film on the Inconel surface, attributed to high frequency process; and finally, in series with the passive film, a second time constant, $R_{\mathrm{ct}} / / C P E_{\mathrm{dl}}$, defining the corrosion process and attributed to low frequency processes. $R_{\text {film }}$ and $C P E_{\text {film }}$ are the parameters defining the passive film, while $R_{\mathrm{ct}}$ and $C P E_{\mathrm{dl}}$ define the charge transfer resistance and the double-layer capacitance, where the $R_{\mathrm{ct}}$ is inversely related to the $i_{\text {corr }}$ by Stern-Geary $[12,29]$. The fitting parameters of the proposed EEC for each of the treatments are seen in Table 3, where an average chi-square $\left(\chi^{2}\right)$ of $10^{-3}$ and an error for each element less than $10 \%$ were obtained.

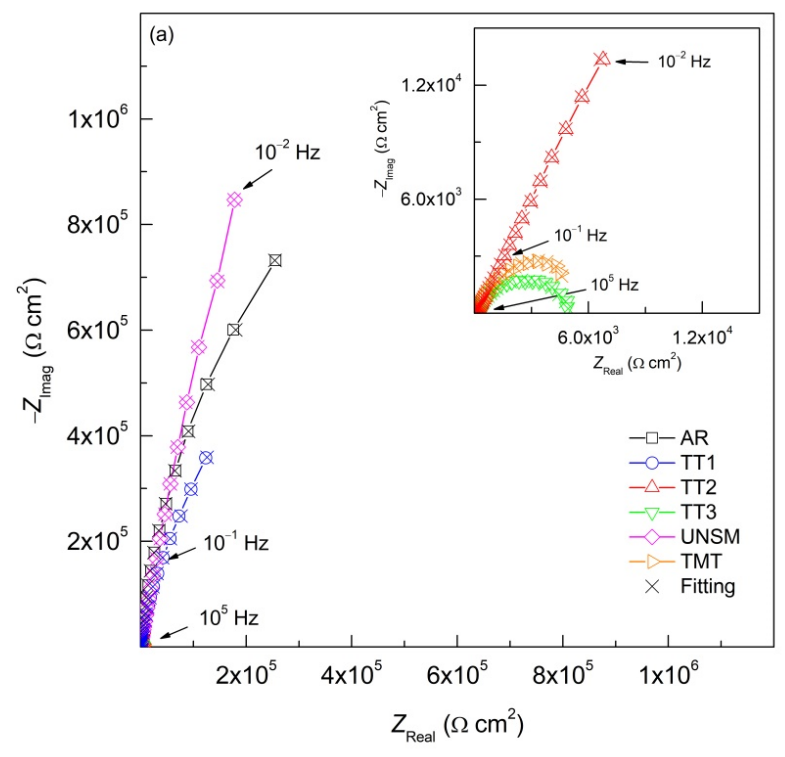

(b)

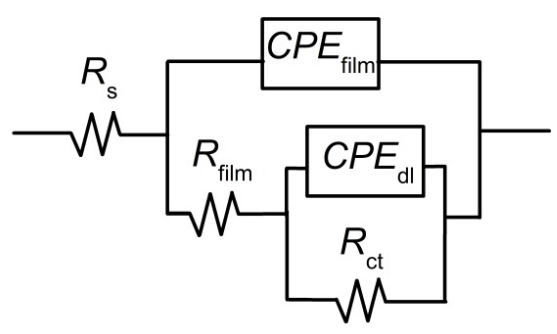

Figure 5. EIS analysis of Inconel 718 in $3.5 \mathrm{wt} . \% \mathrm{NaCl}$ : (a) Nyquist plots for the different treatments, with an inset at higher magnification for the lower frequency data values, and (b) EEC with two time constants. 
Table 3. Fitting EIS parameters for Inconel 718 with the different thermal, mechanical, and thermomechanical treatments.

\begin{tabular}{|c|c|c|c|c|c|c|c|c|c|}
\hline \multirow{2}{*}{ Sample } & $R_{\mathrm{s}}$ & $R_{\text {film }}$ & $Y_{\text {film }}$ & $n_{\text {film }}$ & $R_{\mathrm{ct}}$ & $Y_{\mathrm{dl}}$ & $n_{\mathrm{dl}}$ & $C_{\text {eff,dl }}$ & $x^{2}\left(^{*}\right)$ \\
\hline & $\Omega \mathrm{cm}^{2}$ & $\Omega \mathrm{cm}^{2}$ & $\mathrm{~S} / \mathrm{cm}^{2} \mathrm{~s}$ film & & $\Omega \mathrm{cm}^{2}$ & $\mathrm{~S} / \mathrm{cm}^{2} \mathrm{~s}^{n \mathrm{dl}}$ & \multicolumn{3}{|c|}{$\mu \mathrm{F} / \mathrm{cm}^{2}$} \\
\hline AR & 3.78 & $7.46 \times 10^{5}$ & $2.47 \times 10^{-5}$ & 0.78 & $8.12 \times 10^{5}$ & $1.66 \times 10^{-5}$ & 0.95 & 9.89 & $1.40 \times 10^{-3}$ \\
\hline TT1 & 4.06 & $1.13 \times 10^{5}$ & $9.94 \times 10^{-6}$ & 0.78 & $2.02 \times 10^{5}$ & $2.97 \times 10^{-5}$ & 0.92 & 13.81 & $4.93 \times 10^{-3}$ \\
\hline TT2 & 3.88 & $1.53 \times 10^{3}$ & $1.94 \times 10^{-5}$ & 0.74 & $2.15 \times 10^{4}$ & $5.85 \times 10^{-5}$ & 0.91 & 26.44 & $2.96 \times 10^{-3}$ \\
\hline TT3 & 4.93 & $4.38 \times 10^{2}$ & $3.66 \times 10^{-5}$ & 0.78 & $5.81 \times 10^{3}$ & $1.98 \times 10^{-4}$ & 0.85 & 21.23 & $1.32 \times 10^{-3}$ \\
\hline UNSM & 3.94 & $4.52 \times 10^{5}$ & $1.85 \times 10^{-6}$ & 0.79 & $1.61 \times 10^{6}$ & $1.24 \times 10^{-5}$ & 0.96 & 8.13 & $1.61 \times 10^{-3}$ \\
\hline TMT & 3.48 & $1.27 \times 10^{3}$ & $1.24 \times 10^{-4}$ & 0.78 & $7.13 \times 10^{3}$ & $8.10 \times 10^{-5}$ & 0.83 & 15.12 & $1.14 \times 10^{-3}$ \\
\hline
\end{tabular}

${ }^{*}$ Error $<10 \%$ for all values.

Before the impedance data were further analyzed, Kramers-Kronig transformations were performed, using Equations (1) and (2), to test the robustness [30]:

$$
\begin{gathered}
Z_{\text {Real }}(\omega)=Z_{\text {Real }}(\infty)-\frac{2}{\pi} \int_{0}^{\infty} \frac{x Z_{\text {Imag }}(x)-\omega Z_{\text {Imag }}(\omega)}{x^{2}-\omega^{2}} d x \\
Z_{\text {Imag }}(\omega)=-\frac{2 \omega}{\pi} \int_{0}^{\infty} \frac{x Z_{\text {Real }}(x)-Z_{\text {Real }}(\omega)}{x^{2}-\omega^{2}} d x
\end{gathered}
$$

where $Z_{\text {Real }}(\omega)$ and $Z_{\operatorname{Imag}}(\omega)$ are the real and imaginary portions of the impedance, respectively. $x$ is an integration variable, the value of which is between 0 and $\infty$, and $\omega$ is the angular frequency [31]. From the imaginary component, the real component can be calculated with Equation (1), and vice versa with Equation (2). From this fitting, the data were proved to be robust.

\section{Discussion}

\subsection{Microstructure Characterization}

In addition to the OM characterization, secondary electron SEM images of all crosssection samples were performed to reveal the microstructure and the secondary phases (see Figure 6). The AR sample shows similar microstructure morphology to the one seen in the OM images (see Figure 6a). It shows a purely $\gamma$-phase matrix with some minor $\mathrm{NbC}$ formation, preferentially inside the twins and the triple junctions, sites with higher energy for carbides and secondary phase segregations [32]. These $\mathrm{NbCs}$ are attributed to the TT during the manufacturing process, hence their low population density. The TT1 sample, as seen and previously discussed in the TTT diagram (see Figure 1), shows a high density of $\gamma^{\prime \prime}$-phase at the grain boundaries and some nucleation inside the grains (see Figure $6 \mathrm{~b}$ ). The treatment at $675^{\circ} \mathrm{C}$ for $2 \mathrm{~h}$ shifts the sample inside the $\gamma^{\prime \prime}$-phase region, hence the great difference between the AR and TT1 microstructure. In addition to the precipitation of $\gamma^{\prime \prime}$-phase, which depletes the $\gamma$-phase and migrates $\mathrm{Cr}$ from the grain to the grain boundary, some $\mathrm{NbCs}$ are seen, similar to the AR sample. Once the temperature rises over the solvus of the $\gamma^{\prime} / \gamma^{\prime \prime}$ phase $\left(886^{\circ} \mathrm{C}\right)$, part of the $\gamma^{\prime \prime}$-phase is dissolved from the grain boundaries and diffused into the grain, reducing the population of $\gamma^{\prime \prime}$-phase (see Figure 6c). Furthermore, due to the temperature of $900^{\circ} \mathrm{C}$, there is also a transformation of $\gamma^{\prime \prime}$ to $\delta$-phase as seen in the TTT diagram in Figure 1, further decreasing the population of $\gamma^{\prime \prime}$-phase at the grain boundaries. The annealing treatment of $1000{ }^{\circ} \mathrm{C}$ for $10 \mathrm{~min}$, sample TT3, promotes a scarce formation of equiaxed elongated $\delta$-phase without forming the unstable $\gamma^{\prime \prime}$-phase, evidenced by the small quantity of secondary phases at the grain boundaries (see Figure 6d). Because of the lower exposure time, the density of $\delta$-phase is not as prevalent as the TT2 sample for the $\gamma^{\prime \prime}$-phase. The UNSM sample shows the same morphology and regions as the ones in the microstructure from Figure $2 b$ (see Figure $6 e$ ). The top surface, where the effect of the UNSM processing is concentrated, displays a high plastic deformation, making nearly indistinguishable fine grains. This UNSM region is also populated by deformation twins, increasing the hardness of Inconel 718, as seen by 
the Vickers hardness testing (see Figure 3). Nevertheless, there is no equivalent increase in the nucleation of $\mathrm{NbC}$ s or secondary phases due to the UNSM processing. Finally, the TMT sample presents the regions previously seen in the UNSM sample with the addition of a higher density of $\mathrm{NbCs}$ and $\delta$-phase formation (see Figure $6 \mathrm{f}$ ). The grain refinement at the top surface increases the grain boundary density, promoting more sites for the nucleation of secondary phases and $\mathrm{NbC}$ s once the TT is applied. Moreover, the UNSM processing in addition to the annealing treatment allowed the formation of an oxide scale at the top surface.
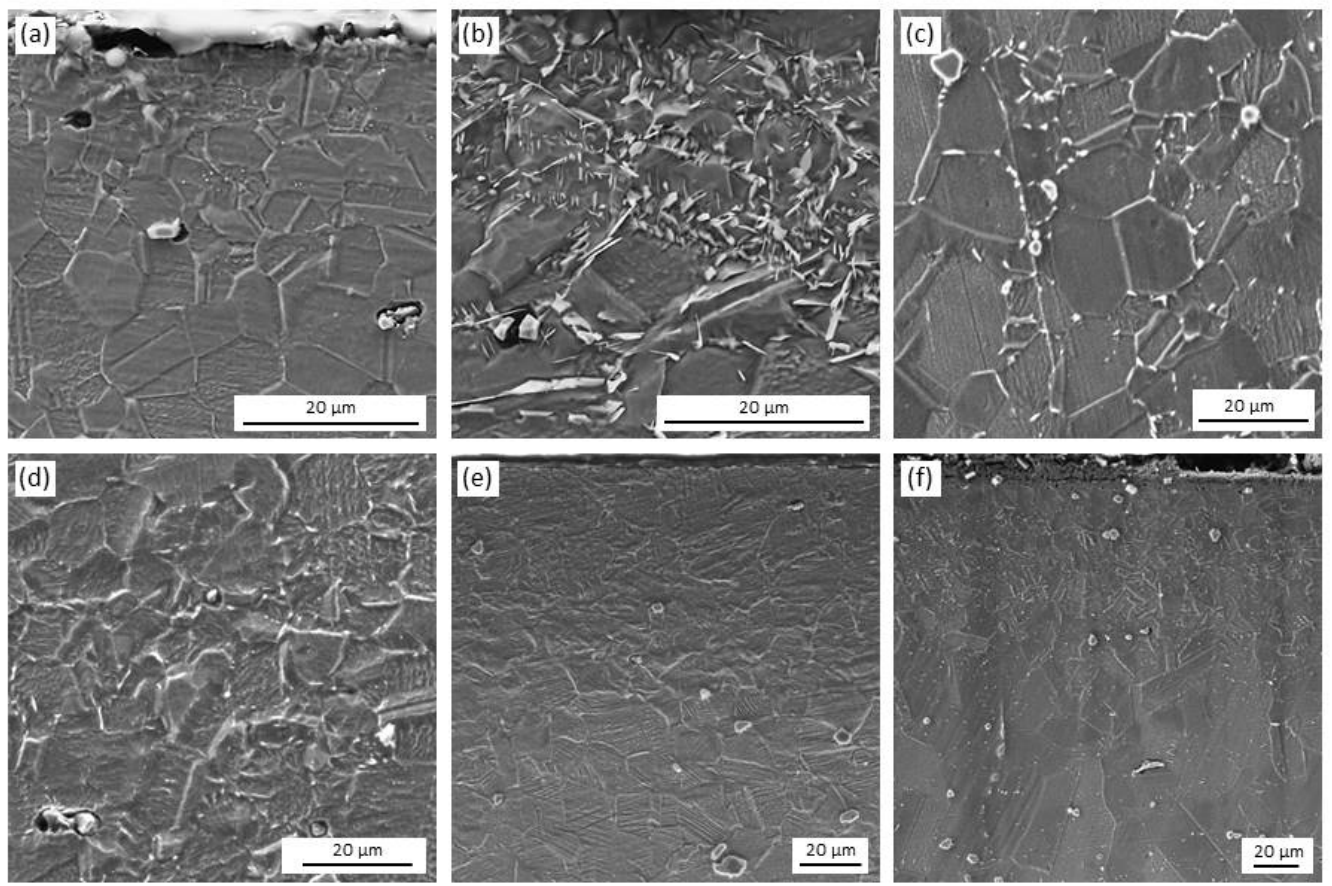

Figure 6. SEM images showing the cross-section microstructure of Inconel $718 \times 600$ : (a) AR sample, (b) TT1 sample, (c) TT2 sample, (d) TT3 sample, (e) UNSM sample, and (f) TMT sample.

In addition to the SEM study, EDX analysis was carried out for sample TT3 to reveal the chemical composition of the promoted $\delta$-phase as well as the niobium carbides $(\mathrm{NbCs})$ (see Figures 7 and 8). The micrograph of sample TT3 shows the previously seen polygonal equiaxed $\gamma$-phase matrix, with the addition of the needle shape $\delta$-phase, promoted by the $1000{ }^{\circ} \mathrm{C}$ for $10 \mathrm{~min}$ treatment as seen in the TTT diagram, and the NbCs formed at the grain boundaries (see Figure 7). The observed amorphous carbide is located at a triple joint, which is a preferential $\mathrm{Cr}$ depletion site originating from the $\mathrm{Cr}$ diffusion process due to the TT [10].

Its elemental composition reveals that the main elements forming it are $\mathrm{Nb}$ and $\mathrm{Ni}$, with 32 and 31 wt.\% respectively, followed by a similar amount of $\mathrm{Cr}$, Fe, and $\mathrm{C}$ with 12, 11 , and $10 \mathrm{wt} . \%$, respectively (see Figure 8a). As previously seen in the SEM analysis, the stable $\delta$-phase is concentrated at the grain boundaries, depleting the $\gamma$ matrix chromium content and increasing the $\mathrm{Nb}$ and $\mathrm{C}$ content (see Figure $8 \mathrm{~b}$ ). Its elemental composition slightly changes from the original (see Figure 8c). 


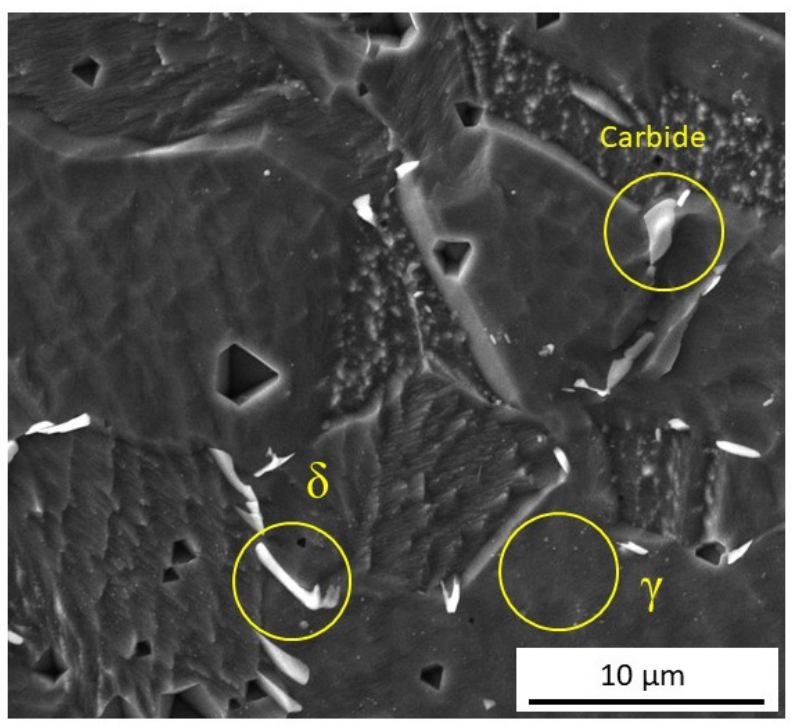

Figure 7. SEM micrograph for the EDX analysis of TT3 sample with the selected areas for the elemental analysis $\times 10,000$.

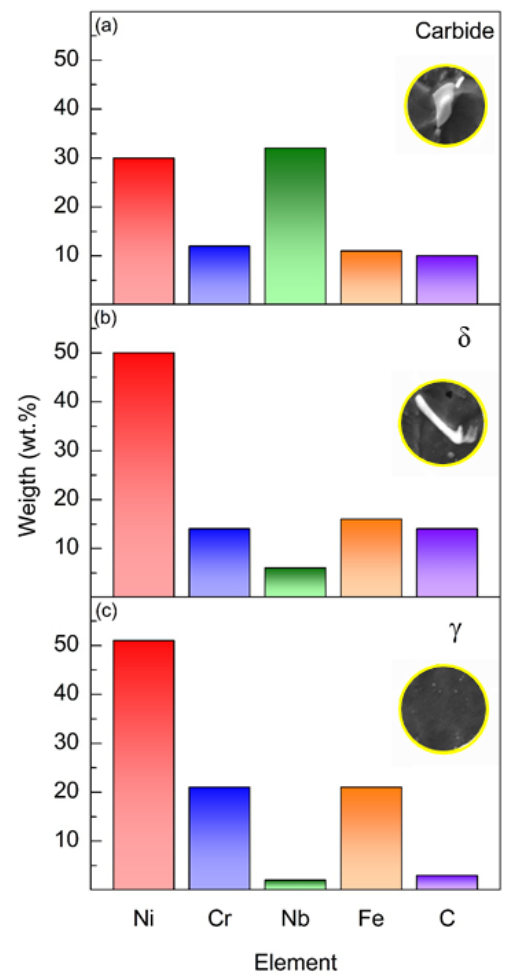

Figure 8. EDX analysis of TT3 sample: (a) elemental composition of the $\mathrm{NbC}$, (b) elemental composition of the $\delta$-phase, and (c) elemental composition of the $\gamma$-phase.

\subsection{Vickers Hardness}

The change in hardness can be related to the corrosion resistance of the sample by the grain size and the microstructure of the sample [33]. Inconel 718 is a super-nickel alloy that promotes a stable $\gamma$-phase matrix thanks to its elemental composition (see Table 1). Based on this composition the stacking fault energy (SFE) can be calculated, giving information of possible microstructure transformation upon a mechanical stimulus, like the one from the UNSM processing [34]. Using Equation (3) the SFE can be calculated:

$\operatorname{SFE}\left(\mathrm{mJ} / \mathrm{m}^{2}\right)=25.7+(2 \times \mathrm{Ni})+(410 \times \mathrm{C})-(0.9 \times \mathrm{Cr})-(77 \times \mathrm{N})-(13 \times \mathrm{Si})-(1.2 \times \mathrm{Mn})$ 
The obtained value of $127.89 \mathrm{~mJ} / \mathrm{m}^{2}$ lies in the dislocation glide region (SFE $>40 \mathrm{~mJ} / \mathrm{m}^{2}$ ), indicating that no strain-induced martensite is promoted by the UNSM processing [35]. As no phase transformation happens due to the processing, all the changes are promoted only by the TT. Hence, the TT is the responsible for the difference in the corrosion behavior between the UNSM and the TMT. The greater grain size, due to the recrystallization of the annealing process, and the formation of carbides by the high temperature of $1000{ }^{\circ} \mathrm{C}$ above the solvus $\gamma^{\prime} / \gamma^{\prime \prime}$ increased the corrosion susceptibility, as seen by previous authors [36]. The higher density of carbides ( $\mathrm{NbCs}$ ) and of more active phases, like the $\gamma^{\prime \prime}$ and $\delta$-phase compared to the $\gamma$-phase, enhanced the susceptibility of Inconel 718 to the chlorides in the solution.

\subsection{Linear Polarization Resistance (LPR)}

The TT1 sample had a lower $E_{\text {corr }}$ compared to the AR sample due to the $\gamma^{\prime} / \gamma^{\prime \prime}$ phase transformation from the $\gamma$-phase matrix, in which the $\gamma$-phase is more stable, thus exhibiting a more noble potential. This transformation was mainly promoted at the grain boundaries due to the temperature range of $675^{\circ} \mathrm{C}$, as seen in Figure $6 \mathrm{~b}$. The $\gamma^{\prime \prime}$-phase is an unstable phase, decreasing the corrosion protection as well as producing micro galvanic coupling with the more stable $\gamma$-phase matrix [37]. TT2 is above the solvus for the $\gamma^{\prime} / \gamma^{\prime \prime}$ $\left(886^{\circ} \mathrm{C}\right)$, reducing the amount of $\gamma^{\prime \prime}$-phase in the grain boundaries but increasing it inside the grain, further depleting the corrosion properties [38]. Finally, TT3 decreases its corrosion protection properties as the annealing temperature of $1000^{\circ} \mathrm{C}$ promotes the formation of $\mathrm{NbCs}$ at the grain boundaries. Accordingly, the $i_{\text {corr }}$ increased with increasing temperature, rising over two orders of magnitude from the AR at $1.22 \times 10^{-8} \mathrm{~A} / \mathrm{cm}^{2}$ to the TT3 at $5.27 \times 10^{-6} \mathrm{~A} / \mathrm{cm}^{2}$. Nevertheless, the UNSM treatment, with its grain refinement and higher dislocations on the top surface, only degraded its $E_{\text {corr }}$ by $70 \mathrm{mV}$; however, it lowered its $i_{\text {corr }}$ to $1.30 \times 10^{-8} \mathrm{~A} / \mathrm{cm}^{2}$, a sign of its enhanced pitting corrosion protection [14]. The more active surface, once it is in contact with the $\mathrm{pH}$ near-neutral solution, is able to form a passive film rich in Cr oxides, which serves as a protective barrier against the $\mathrm{Cl}^{-}$in the solution [37]. In addition, the low chloride content of $3.5 \mathrm{wt} . \% \mathrm{NaCl}$ for Inconel 718 is not enough to dissolve the passive film and produce pitting. Nonetheless, the TMT sample decreased its $E_{\text {corr }}$ to values similar to the TT3, reaching the $-410 \mathrm{mV}$ versus SCE and having an $i_{\text {corr }}$ of $4.12 \times 10^{-6} \mathrm{~A} / \mathrm{cm}^{2}$. The increased density of grain boundaries of the TMT sample combined with the $1000{ }^{\circ} \mathrm{C}$ enhances the pitting corrosion susceptibility by the formation of $\mathrm{NbCs}$ shown in Figure $6 \mathrm{f}$.

\subsection{Electrochemical Impedance Spectroscopy (EIS)}

The $R_{\mathrm{S}}$ for all samples was between 3.48 and $4.93 \Omega \mathrm{cm}^{2}$. The $R_{\text {film }}$ of the AR started with $7.46 \times 10^{5} \Omega \mathrm{cm}^{2}$ followed by the TT1 with $1.13 \times 10^{5} \Omega \mathrm{cm}^{2}$. TT2 and TT3 show a decrease of two and three orders of magnitude, reaching $1.53 \times 10^{3}$ and $4.38 \times 10^{2} \Omega \mathrm{cm}^{2}$, respectively. As it was seen with the $i_{\text {corr }}$ trend, the increasing temperature decreases the impedance response, which is related to the corrosion protection behavior against the chlorides of the sample, promoting $\mathrm{NbCs}$ and secondary phases that are more active than the $\gamma$-phase. The UNSM processing, with its grain refinement, increases the $R_{\text {film }}$ to values close to the AR, with $4.52 \times 10^{5} \Omega \mathrm{cm}^{2}$. Nevertheless, the TMT reduced its value to a $1.27 \times 10^{3} \Omega \mathrm{cm}^{2}$ intermediate value between the TT2 and TT3, coinciding with the LPR behavior seen for the $i_{\text {corr. }}$. The $C P E_{\text {film }}$, with its $Y_{\text {film }}$, pseudo-capacitance shows an increasing trend with the rising temperature, suggesting a thinning of the passive film, as the thickness is inversely related to the capacitance, with values ranging from 1.85 to $124 \mu \mathrm{S} / \mathrm{cm}^{2}$. The $n_{\text {film }}$ factor indicating the ideality of the capacitor remains largely unchanged for all samples at approximately 0.780 [39]. AR shows one of the highest $R_{\mathrm{ct}}$ values with $8.12 \times 10^{5} \Omega \mathrm{cm}^{2}$, due to the unmodified $\gamma$-phase matrix. After the thermal treatments, the $R_{\mathrm{ct}}$ decreases as previously seen with the LPR test, and the TT1 does not decrease considerably reaching $2.02 \times 10^{5} \Omega \mathrm{cm}^{2}$. However, TT2 and TT3 specimens rapidly drop as the solvus for $\gamma^{\prime} / \gamma^{\prime \prime}$ is passed, with $2.15 \times 10^{4}$ and $5.81 \times 10^{3} \Omega \mathrm{cm}^{2}$, respectively. 
The phase transformation from the TTT diagram from the $\gamma$-phase to the $\gamma^{\prime \prime}$ and $\delta$-phase and the nucleation of $\mathrm{NbCs}$ at the grain boundaries reduce the corrosion resistance of the passive film (see Figure 1). The UNSM increases the $R_{\mathrm{ct}}$ over the AR showing a value of $1.61 \times 10^{6} \Omega \mathrm{cm}^{2}$, as seen in Figure 5a, enhancing the corrosion protection of the sample against the chlorides in the solution. Finally, the TMT sample reaches a similar value to the TT3, which has the same thermal treatment, despite having the UNSM process (see Table 3). The recrystallization of the grains plus the formation of $\mathrm{NbCs}$ is more detrimental to the corrosion properties than the bust from the grain refinement from the UNSM processing. The $Y_{\mathrm{dl}}$ of the $C P E_{\mathrm{dl}}$, related to the corrosion properties of the double layer, is mainly in the tens of $\mu \mathrm{S} / \mathrm{cm}^{2}$ range, similar to the $Y_{\text {film }}$, with the exception of the TT3 and TMT, which lie above the solvus of $\gamma^{\prime} / \gamma^{\prime \prime}$, increasing their values to $1.98 \times 10^{-4}$ and $8.10 \times 10^{-5} \mathrm{~S} / \mathrm{cm}^{2}$, respectively. To further check the robustness of the results, the $R_{\mathrm{ct}}$ values were compared between the LPR (DC method) and the EIS tests (AC method), plotted together in Figure 9, where the $R_{\mathrm{ct}}$ values of the LPR were corrected from the ohmic drop effect, as described in the LPR section. Both sets of $R_{\mathrm{ct}}$ values are close to each other, being in the same order of magnitude for all the samples. The obtained results using different methods, DC and AC, are in good agreement and are consistent with each other.

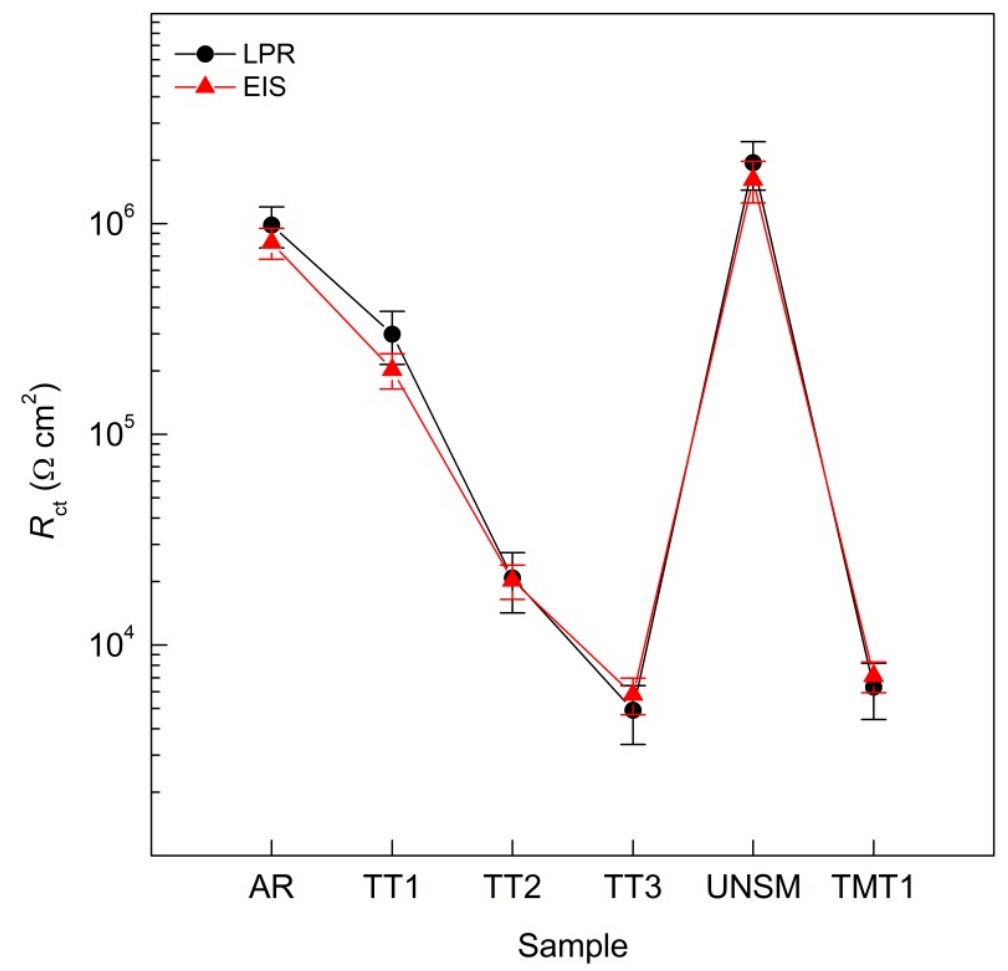

Figure 9. $R_{\mathrm{ct}}$ comparison between LPR and EIS techniques of Inconel 718 samples in $3.5 \mathrm{wt} . \% \mathrm{NaCl}$.

The $C P E$ elements present in the EEC represent a branched ladder $R C$ network, hence a non-ideal capacitor, indicating that the capacitance cannot be measured directly from its value [40]. In order to correct the pseudo-capacitance value of the $C P E_{\mathrm{dl}}$ and find its effective capacitance $\left(C_{\text {eff,dl }}\right)$, Brug et al. proposed taking into account not only the $Y_{\mathrm{dl}}$ and $n_{\mathrm{dl}}$ but also the resistance of the electrolyte and the charge transfer resistance, $R_{\mathrm{s}}$ and $R_{\mathrm{ct}}$, respectively (see Equation (4)) [39,41]:

$$
C_{\mathrm{eff}, \mathrm{dl}}=\left[Y_{\mathrm{dl}}\left(\frac{1}{R_{\mathrm{s}}}+\frac{1}{R_{\mathrm{ct}}}\right)^{\left(n_{\mathrm{dl}}-1\right)}\right]^{\frac{1}{n_{\mathrm{dl}}}}
$$


The corrected $C_{\text {eff,dl }}$ values are plotted in Figure 10 , where the estimated thickness is also added using the inverse relationship seen in Equation (5):

$$
C_{\mathrm{eff}, \mathrm{dl}}=\frac{\varepsilon_{\mathrm{o}} \varepsilon_{\mathrm{film}} A}{d}
$$

where $\varepsilon_{\mathrm{O}}$ is the dielectric constant of the permittivity of the vacuum $\left(8.84 \times 10^{-14}\right), \varepsilon_{\text {film }}$ is the dielectric constant of the oxide film (a value of 15 was used for the passive film formed in stainless steel), $A$ is the exposed surface area, and $d$ is the thickness of the passive film $[42,43]$. The $C_{\text {eff, } d l}$ values are all in the tens of $\mu \mathrm{F} / \mathrm{cm}^{2}$, ranging from 8.13 to $26.41 \mu \mathrm{F} / \mathrm{cm}^{2}$. The corresponding thickness of the double layer is also constant in the $\mathrm{nm}$ range, with a minimum of $0.52 \mathrm{~nm}$ for TT2 and a maximum of $1.70 \mathrm{~nm}$ for the UNSM. The thickest passive film observed for the UNSM treated sample is in good agreement with the previous results, as the UNSM treatment concentrates more energy and activates the top surface growth reaction kinetics, enabling a faster formation and growth of the passive film in the near-neutral $\mathrm{pH}$ of the $3.5 \mathrm{wt}$ \% $\mathrm{NaCl}$ solution.

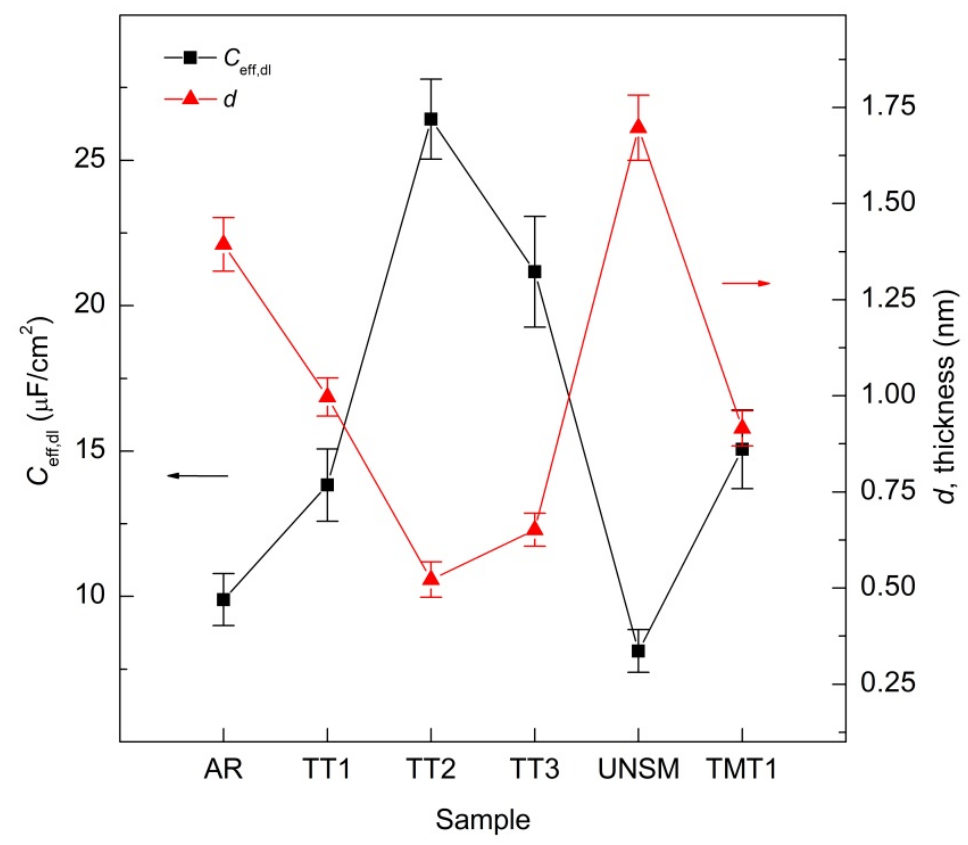

Figure 10. $C_{\text {eff,dl }}$ and thickness of the passive film $(d)$ of Inconel 718 samples in $3.5 \mathrm{wt} . \% \mathrm{NaCl}$.

\subsection{Infinite Focus Microscopy (IFM)}

Figure 11 shows the IFM images at $\times 100$ magnification of all Inconel 718 samples after the electrochemical testing in $3.5 \mathrm{wt} . \% \mathrm{NaCl}$. The AR showed the most uniform top surface, where only some minor dissolution was observed (see Figure 11a). Overall, the AR did not show any sign of pitting. The TT1 sample started degrading from the AR condition as more areas with deeper grooves were seen (see Figure 11b). The TT2 sample continued with the increasing depth in the dissolution, reaching $600 \mathrm{~nm}$ (see Figure 11c). The TT above the $\gamma^{\prime} / \gamma^{\prime \prime}$ solvus temperature showed a significant effect, as previously seen in the EIS testing, degrading the corrosion protection of the passive film (see Figures 3 and 6). Once the $1000{ }^{\circ} \mathrm{C}$ treatment was applied to the Inconel 718 sample, the majority of the top surface seemed to have some dissolution within the 100 to $300 \mathrm{~nm}$ depth (see Figure 11d). The UNSM sample did not show much corrosion, only some minor areas with some dissolution (see Figure 11e). For the remainder of the surface area, the UNSM sample showed a homogeneous surface, coinciding with the enhanced corrosion protection seen in the previous electrochemical section. Finally, the TMT sample showed that, even with UNSM processing, the TT of $1000{ }^{\circ} \mathrm{C}$ was detrimental for corrosion protection, showing considerable areas where the depth of the dissolution reached an average of 400 to $600 \mathrm{~nm}$ 
(see Figure 11f). This dissolution was not as concentrated as the TT3 sample, but it was still covering a great area of the top surface.

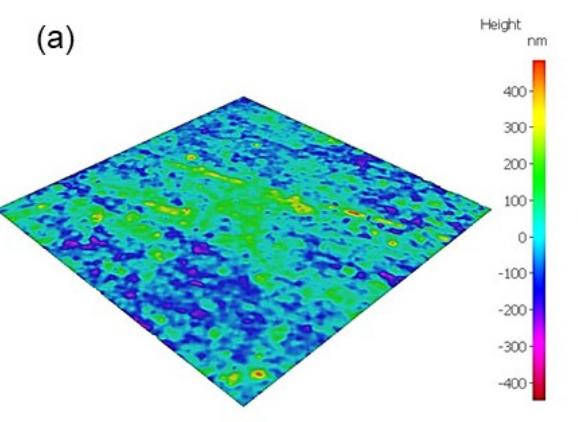

(d)

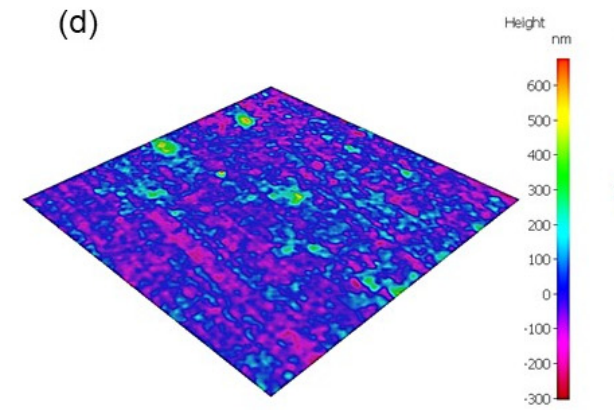

(b)
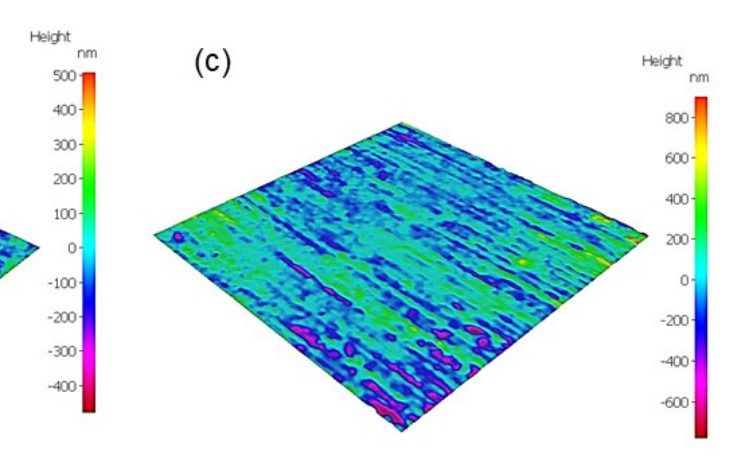

(e)
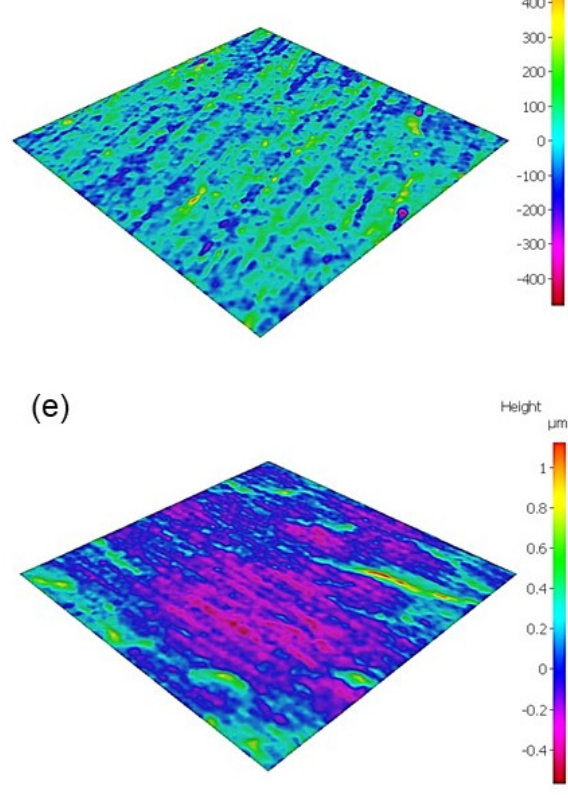

(f)

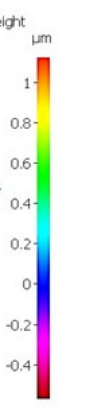

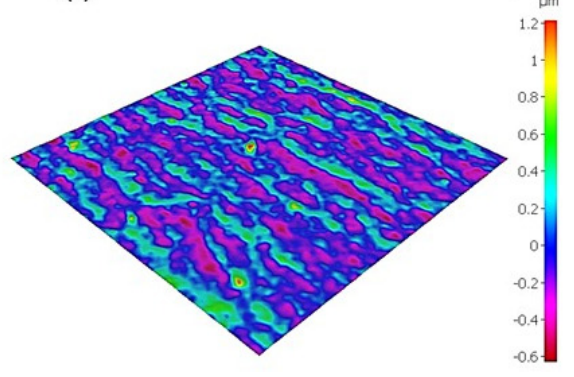

Figure 11. IFM images of the top surface of Inconel 718 after the exposure to the $3.5 \mathrm{wt} . \% \mathrm{NaCl} \times 100$ : (a) AR sample, (b) TT1 sample, (c) TT2 sample, (d) TT3 sample, (e) UNSM sample, and (f) TMT sample.

\section{Conclusions}

In this work, the influence of the TT and TMT on Inconel 718 using the UNSM treatment on the corrosion behavior was studied. The main conclusions can be drawn as follows:

The UNSM process increased the pitting corrosion protection of Inconel 718 in $3.5 \mathrm{wt} . \%$ $\mathrm{NaCl}$ compared to the AR and the other TT samples, due to the active surface that the UNSM formed, enabling a faster growth of the passive film.

The phase transformation of the $\gamma$-phase to $\gamma^{\prime}$ by the TT diagram $\gamma^{\prime \prime}$ and $\delta$-phases implied a reduction of the corrosion protection, seen in the lower $R_{\mathrm{ct}}$ values from the EIS and LPR. Even with the grain refinement of the UNSM process, which enhanced the corrosion protection, the TMT had low impedance values due to the dense formation of $\mathrm{NbCs}$.

Temperatures above the solvus of the $\gamma^{\prime} / \gamma^{\prime \prime}$ and close to the solvus of the $\delta$-phase, shifted the $E_{\text {corr }}$ towards more active potentials, and the $i_{\text {corr }}$ towards higher values, leading to a higher pitting corrosion susceptibility due to the precipitation of $\mathrm{NbCs}, \gamma^{\prime \prime}$ and $\delta$-phases.

The hardness increased with the UNSM treatment up to $450 \mathrm{HV}$, while the TMT only increased to $340 \mathrm{HV}$ due to the addition of the annealing process recrystallizing the grains and reducing the dislocations. Nevertheless, both treatments had higher hardness than the $285 \mathrm{HV}$ of the AR.

The pit density and pit depth increased with the increasing temperature, coinciding with the higher $i_{\text {corr }}$ values obtained by the LPR. While the USNM process only promoted some scarce pits, the TMT obtained greater areas with deeper pits due to the abundant $\mathrm{NbCs}$.

Author Contributions: Conceptualization, D.M.B.; Methodology, U.M., J.R. and D.M.B.; Experimental design, U.M., J.R. and D.M.B.; Data analysis, U.M., J.R. and D.M.B.; Resources, D.M.B.; Writing—original draft preparation, U.M., J.R. and D.M.B.; Writing—review and editing, U.M., J.R. 
and D.M.B.; Visualization, D.M.B.; Supervision, D.M.B.; Project administration, D.M.B.; Funding acquisition, D.M.B. All authors have read and agreed to the published version of the manuscript.

Funding: This research was funded by Firestone Research, grant number 639430, and The University of Akron Fellowship FRC-207160.

Institutional Review Board Statement: Not applicable.

Informed Consent Statement: Not applicable.

Data Availability Statement: The raw/processed data required to reproduce these findings cannot be shared at this time as the data also form part of an ongoing study.

Acknowledgments: The authors acknowledge the technical support and facilities from The National Center for Education and Research on Corrosion and Materials Performance (NCERCAMP-UA), The College of Engineering and Polymer Science and The University of Akron.

Conflicts of Interest: The authors declare no conflict of interest.

\section{References}

1. Azadian, S.; Wei, L.Y.; Warren, R. Delta phase precipitation in Inconel 718. Mater. Charact. 2004, 53, 7-16. [CrossRef]

2. Hosseini, E.; Popovich, V.A. A review of mechanical properties of additively manufactured Inconel 718. Addit. Manuf. 2019, 30, 100877. [CrossRef]

3. Zhang, H.; Li, C.; Guo, Q.; Ma, Z.; Huang, Y.; Li, H.; Liu, Y. Hot tensile behavior of cold-rolled Inconel 718 alloy at $650{ }^{\circ} \mathrm{C}$ : The role of $\delta$ phase. Mater. Sci. Eng. A 2018, 722, 136-146. [CrossRef]

4. Kang, Y.J.; Yang, S.; Kim, Y.K.; AlMangour, B.; Lee, K.A. Effect of post-treatment on the microstructure and high-temperature oxidation behaviour of additively manufactured Inconel 718 alloy. Corros. Sci. 2019, 158, 108082. [CrossRef]

5. Campos-Silva, I.; Contla-Pacheco, A.D.; Figueroa-López, U.; Martínez-Trinidad, J.; Garduño-Alva, A.; Ortega-Avilés, M. Sliding wear resistance of nickel boride layers on an Inconel 718 superalloy. Surf. Coat. Technol. 2019, 124862. [CrossRef]

6. Zhang, H.; Li, C.; Liu, Y.; Guo, Q.; Huang, Y.; Li, H.; Yu, J. Effect of hot deformation on $\gamma^{\prime \prime}$ and $\delta$ phase precipitation of Inconel 718 alloy during deformation\&isothermal treatment. J. Alloys Compd. 2017, 716, 65-72. [CrossRef]

7. Jelvani, S.; Shoja Razavi, R.; Barekat, M.; Dehnavi, M.R.; Erfanmanesh, M. Evaluation of solidification and microstructure in laser cladding Inconel 718 superalloy. Opt. Laser Technol. 2019, 120, 105761. [CrossRef]

8. Kulkarni, A.; Dwivedi, D.K.; Vasudevan, M. Dissimilar metal welding of P91 steel-AISI 316L SS with Incoloy 800 and Inconel 600 interlayers by using activated TIG welding process and its effect on the microstructure and mechanical properties. J. Mater. Process. Technol. 2019, 274, 116280. [CrossRef]

9. Kañetas, P.P.; Osorio, L.R.; Mata, M.G.; De La Garza, M.; López, V.P. Influence of the delta phase in the microstructure of the Inconel 718 subjected to "Delta-processing" heat treatment and hot deformed. Procedia Mater. Sci. 2015, 8, 1160-1165. [CrossRef]

10. Rafiei, M.; Mirzadeh, H.; Malekan, M. Micro-mechanisms and precipitation kinetics of delta $(\delta)$ phase in Inconel 718 superalloy during aging. J. Alloys Compd. 2019, 795, 207-212. [CrossRef]

11. Anderson, M.; Thielin, A.L.; Bridier, F.; Bocher, P.; Savoie, J. $\delta$ Phase precipitation in Inconel 718 and associated mechanical properties. Mater. Sci. Eng. A 2017, 679, 48-55. [CrossRef]

12. Luo, S.; Huang, W.; Yang, H.; Yang, J.; Wang, Z.; Zeng, X. Microstructural evolution and corrosion behaviors of Inconel 718 alloy produced by selective laser melting following different heat treatments. Addit. Manuf. 2019, 30, 100875. [CrossRef]

13. Gill, A.; Telang, A.; Mannava, S.R.; Qian, D.; Pyoun, Y.S.; Soyama, H.; Vasudevan, V.K. Comparison of mechanisms of advanced mechanical surface treatments in nickel-based superalloy. Mater. Sci. Eng. A 2013, 576, 346-355. [CrossRef]

14. Bazarbayev, Y.; Kattoura, M.; Mao, K.S.; Song, J.; Vasudevan, V.K.; Wharry, J.P. Effects of corrosion-inhibiting surface treatments on irradiated microstructure development in Ni-base alloy 718. J. Nucl. Mater. 2018, 512, 276-287. [CrossRef]

15. Amanov, A.; Pyun, Y.S. Local heat treatment with and without ultrasonic nanocrystal surface modification of Ti-6Al-4V alloy: Mechanical and tribological properties. Surf. Coat. Technol. 2017, 326, 343-354. [CrossRef]

16. Kattoura, M.; Mannava, S.R.; Qian, D.; Vasudevan, V.K. Effect of ultrasonic nanocrystal surface modification on elevated temperature residual stress, microstructure, and fatigue behavior of ATI 718Plus alloy. Int. J. Fatigue 2018, 110, 186-196. [CrossRef]

17. Amanov, A.; Umarov, R. The effects of ultrasonic nanocrystal surface modification temperature on the mechanical properties and fretting wear resistance of Inconel 690 alloy. Appl. Surf. Sci. 2018, 441, 515-529. [CrossRef]

18. Martin, U.; Ress, J.; Bosch, J.; Bastidas, D.M. Evaluation of the DOS by DL-EPR of UNSM processed Inconel 718. Metals 2020, 10, 204. [CrossRef]

19. Zhao, W.; Liu, D.; Qin, H.; Zhang, X.; Zhang, H.; Zhang, R.; Ren, Z.; Ma, C.; Amanov, A.; Pyun, Y.-S.; et al. The effect of ultrasonic nanocrystal surface modification on low temperature nitriding of ultra-high strength steel. Surf. Coat. Technol. 2019, 375, 205-214. [CrossRef]

20. Kim, K.-T.; Lee, J.-H.; Kim, Y.-S. Effect of ultrasonic nano-crystal surface modification (UNSM) on the passivation behavior of aged 316L stainless steel. Materials 2017, 10, 713. [CrossRef] [PubMed] 
21. Li, X.; Shi, J.J.; Cao, G.H.; Russell, A.M.; Zhou, Z.J.; Li, C.P.; Chen, G.F. Improved plasticity of Inconel 718 superalloy fabricated by selective laser melting through a novel heat treatment process. Mater. Des. 2019, 180, 107915. [CrossRef]

22. Chandrasekar, R.; Lo, C.C.H.; Frishman, A.M.; Larson, B.F.; Nakagawa, N. Quantification of precipitates and their effects on the response of nickel-base superalloy to shot peening. AIP Conf. Proc. 2012, 1430, 1437-1444.

23. ASTM G3-14. Standard Practice for Conventions Applicable to Electrochemical Measurements in Corrosion Testing; ASTM International: West Conshohocken, PA, USA, 2019. [CrossRef]

24. ASTM E112-13. Standard Test Methods for Determining Average Grain Size; ASTM International: West Conshohocken, PA, USA, 2013. [CrossRef]

25. Kattoura, M.; Telang, A.; Mannava, S.R.; Qian, D.; Vasudevan, V.K. Effect of Ultrasonic Nanocrystal Surface Modification on residual stress, microstructure and fatigue behavior of ATI 718Plus alloy. Mater. Sci. Eng. A 2018, 711, 364-377. [CrossRef]

26. Babu, U.R.; Kondraivendhan, B. Effect of IR drop on reinforced concrete corrosion measurements. IOP Conf. Ser. Mater. Sci. Eng. 2020, 829, 012015. [CrossRef]

27. Cui, Z.; Wang, L.; Ni, H.; Hao, W.; Man, C.; Chen, S.; Wang, X.; Liu, Z.; Li, X. Influence of temperature on the electrochemical and passivation behavior of 2507 super duplex stainless steel in simulated desulfurized flue gas condensates. Corros. Sci. 2017, 118, 31-48. [CrossRef]

28. Bastidas, D.M.; Fernández-Jiménez, A.; Palomo, A.; González, J.A. A study on the passive state stability of steel embedded in activated fly ash mortars. Corros. Sci. 2008, 50, 1058-1065. [CrossRef]

29. Bautista, A.; Paredes, E.C.; Velasco, F.; Alvarez, S.M. Corrugated stainless steels embedded in mortar for 9 years: Corrosion results of non-carbonated, chloride-contaminated samples. Constr. Build. Mater. 2015, 93, 350-359. [CrossRef]

30. Ohta, K.; Ishida, H. Comparison among several numerical integration methods for Kramers-Kronig transformation. Appl. Spectrosc. 1988, 42, 952-957. [CrossRef]

31. Ress, J.; Martin, U.; Bosch, J.; Bastidas, D.M. pH-Triggered release of $\mathrm{NaNO}_{2}$ corrosion inhibitors from novel colophony microcapsules in simulated concrete pore solution. ACS Appl. Mater. Interfaces 2020, 12, 46686-46700. [CrossRef]

32. Nabavi, B.; Goodarzi, M.; Khan, A.K. Metallurgical effects of nitrogen on the microstructure and hot corrosion behavior of alloy 718 weldment. Mater. Charact. 2019, 157, 109916. [CrossRef]

33. Alizadeh, M.; Bordbar, S. The influence of microstructure on the protective properties of the corrosion product layer generated on the welded API X70 steel in chloride solution. Corros. Sci. 2013, 70, 170-179. [CrossRef]

34. Pierce, D.T.T.; Jiménez, J.A.A.; Bentley, J.; Raabe, D.; Wittig, J.E.E. The influence of stacking fault energy on the microstructural and strain-hardening evolution of Fe-Mn-Al-Si steels during tensile deformation. Acta Mater. 2015, 100, 178-190. [CrossRef]

35. Meric de Bellefon, G.; van Duysen, J.C.; Sridharan, K. Composition-dependence of stacking fault energy in austenitic stainless steels through linear regression with random intercepts. J. Nucl. Mater. 2017, 492, 227-230. [CrossRef]

36. Weng, S.; Huang, Y.H.; Xuan, F.Z.; Luo, L.H. Correlation between microstructure, hardness and corrosion of welded joints of disc rotors. Procedia Eng. 2015, 130, 1761-1769. [CrossRef]

37. Zhang, B.; Xiu, M.; Tan, Y.T.; Wei, J.; Wang, P. Pitting corrosion of SLM Inconel 718 sample under surface and heat treatments. Appl. Surf. Sci. 2019, 490, 556-567. [CrossRef]

38. Huang, G.; Liu, G.Q.; Feng, M.; Zhang, M.; Hu, B.; Wang, H. The effect of cooling rates from temperatures above the $\gamma^{\prime}$ solvus on the microstructure of a new nickel-based powder metallurgy superalloy. J. Alloys Compd. 2018, 747, 1062-1072. [CrossRef]

39. Hirschorn, B.; Orazem, M.E.; Tribollet, B.; Vivier, V.; Frateur, I.; Musiani, M. Determination of effective capacitance and film thickness from constant-phase-element parameters. Electrochim. Acta 2010, 55, 6218-6227. [CrossRef]

40. Bastidas, D.M. Interpretation of impedance data for porous electrodes and diffusion processes. Corrosion 2007, 63, 515-521. [CrossRef]

41. Huang, V.M.W.; Vivier, V.; Orazem, M.E.; Pébère, N.; Tribollet, B. The apparent constant-phase-element behavior of a disk electrode with faradaic reactions a global and local impedance analysis. J. Electrochem. Soc. 2007, 154, C99-C107. [CrossRef]

42. Hakiki, N.B.; Boudin, S.; Rondot, B.; Da Cunha Belo, M. The electronic structure of passive films formed on stainless steels. Corros. Sci. 1995, 37, 1809-1822. [CrossRef]

43. Fajardo, S.; Bastidas, D.M.; Criado, M.; Bastidas, J.M. Electrochemical study on the corrosion behaviour of a new low-nickel stainless steel in carbonated alkaline solution in the presence of chlorides. Electrochim. Acta 2014, 129, 160-170. [CrossRef] 